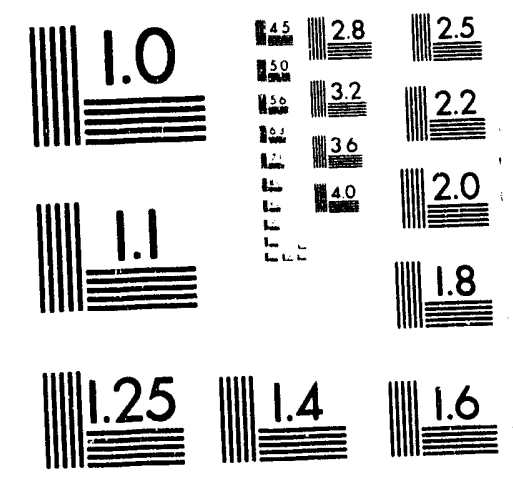



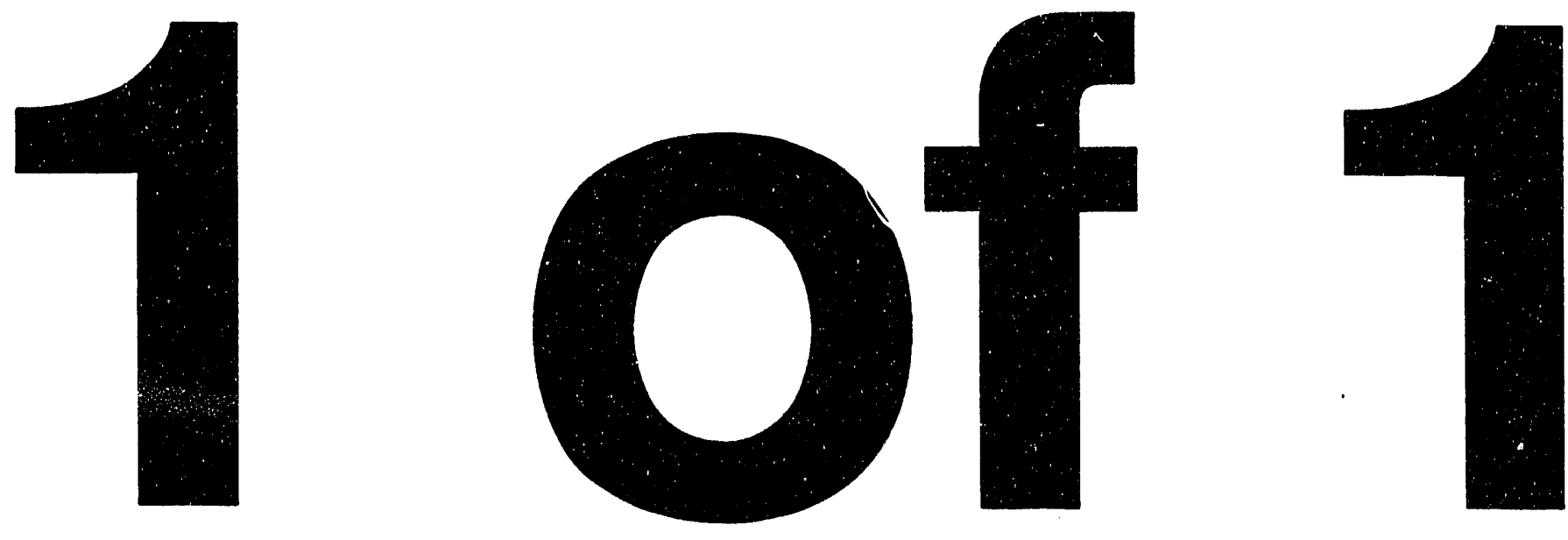
UCRL-JC-114575

PREPRINT

CONF- $430676-46$

\section{ELECTRICAL CONDUCTIVITY OF HYDROGEN SHOCKED TO MEGABAR PRESSIRES}

\section{S.T. Weir, W.J. Nellis, and A.C. Mitchell}

This paper was prepared for the Joint AIRAPT/APS Topical Conference on High Pressure Science and Technology

Colorado Springs, CO

June 28 - July 2, 1993

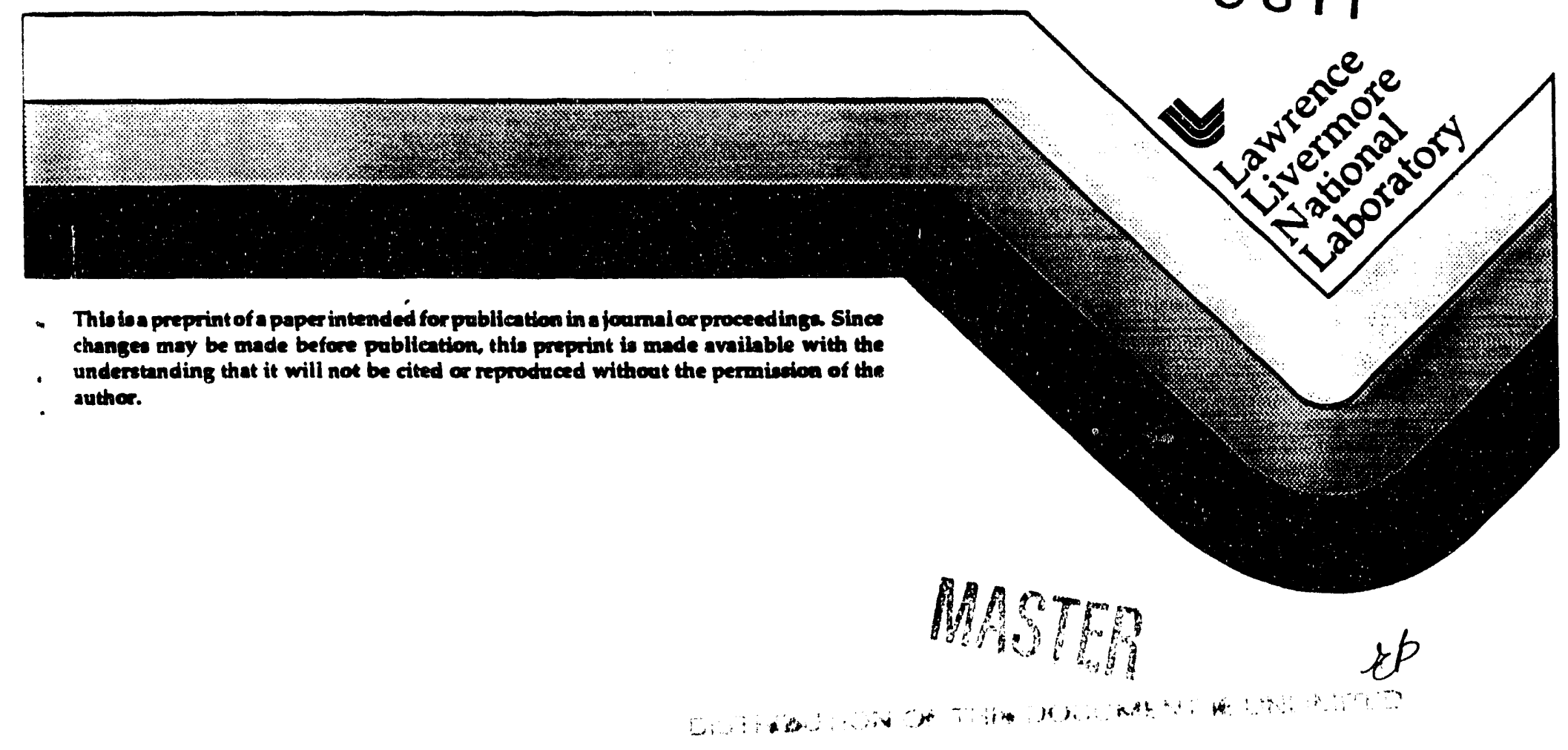


This document was prepared as an accoumt of work sponsored by an agency of the United States Government. Neither the United States Government nor the University of California nor any of their employees, makes any warranty. express or implied. or assumes any legal liability or responsibility for the accuracy, completeness, or usefulness of any information, apparatus, product. or process disclosed, or represemts that its use would $n \alpha$ infringe privately owned rights. Reference herein to any specific commercial products, process. or service by trade name, trademart, manufacturer, or otherwise, does not necesarily constitute or imply its endorsement, recommendation. or favoring by the United States Government or the Unjversity of California. The views and opinions of authors expressed berein do now necessarily state or reflect thoee of the United States Government or the University of California. and shall not be used for advertising or product endorsement purposes. 


\title{
ELECTRICAL CONDUCTIVITY OF HYDROGEN SHOCKED TO MEGABAR PRESSURES
}

\author{
S.T. Weir, W.J. Nellis, and A.C. Mitchell \\ Lawrence Livermore National Laboratory \\ University of California, P.O. Box 808 \\ Livermore, CA 94550
}

\begin{abstract}
Electrical conductivity experiments on compressed hydrogen are valuable for determining the band gap of hydrogen at near-metallic densities, and for estimating the bandoverlap metallization density of hydrogen. In our experiments, liquid hydrogen samples were quasi-isentropically compressed to megabar pressures by a reverberating shock wave, and the electrical conductivities were measured simultaneously. To check for consistency, experiments were performed with both $\mathrm{H}_{2}$ and $\mathrm{D}_{2}$. Preliminary analysis shows that the measured electrical conductivities are consistent with an intrinsic semiconductor model in which conduction occurs by thermal excitation of charge carriers across the electronic band gap of molecular hydrogen. Thus, the conductivity measurements yield valuable information on the band gap of hydrogen at densities approaching the metallization density. Pressures ranged from 0.8 to $1.2 \mathrm{Mbars}$, and calculated temperatures from $2000 \mathrm{~K}$ to $3000 \mathrm{~K}$. The calculated densities were near 0.3 moles/cc. Calculated temperatures are small compared to the band gap. Measured conductivities are in agreement with electronic band gap calculations ${ }^{1}$ for orientationally disordered hcp $\mathrm{H}_{2}$; the theory for this situation predicts band gaps of 6.0 to $5.2 \mathrm{eV}$ in this range.
\end{abstract}

${ }^{1}$ H. Chasham and S.G. Louie, Phys. Rev. Lett. 66, 64 (1991).

\section{INTRODUCTION}

The properties of ultra-high pressure hydrogen have been the subject of much experimental ${ }^{1-9}$ and theoretical ${ }^{10-14}$ study. Of particular interest is the pressure-induced insulator-to-metal (I-M) transition of hydrogen which, according to recent theoretical calculations ${ }^{14}$, is predicted to occur by band-overlap in the pressure range of 1.5-3.0 Mbars on the zero temperature isotherm. Extreinely high pressures are required for rietallization since the low-pressure barid gap is about $15 \mathrm{eV}$. Recent static-pressure diamond anvil cell experiments have searched for evidence of an insulator-tometal transition, but no conclusive evidence for such a transition has yet been supplied. Providing conclusive evidence for hydrogen metallization is difficult because no technique has yet been developed for performing static highpressure electrical conductivity experiments at megabar pressures.

We report here on electrical conductivity experiments performed on $\mathrm{H}_{2}$ and
$\mathrm{D}_{2}$ multi-shocked to megabar pressures. Electrical conductivities of dense fluid hydrogen at these pressures and temperatures reached are needed for calculations of the magnetic fields of Jupiter and Saturn ${ }^{15}$, the magnetic fields being generated by convective dynamos of hot, dense, semiconducting fluid hydrogen. Also, since electrical conduction at the pressure-temperature conditions being studied is due to the thermal excitation of charge carriers across the electronic band gap, these experiments yield valuable information on the width of the band gap at high densities.

\section{EXPERIMENT}

\section{Multi-Shock Compression of Hydrogen}

Our experiments involve compressing starting samples of liquid hydrogen with a rapid succession of shocks. The amount of irreversible shock heating in our multi-shock experiments is much less than that for single shock experiments to the same pressure. Thus, multi- 
shocking results in a quasi-isentropic compression of the sample and very high densities can be attained. A schematic of the target region is shown in Figure 1. The target was first cooled to $20 \mathrm{~K}$ by circulating liquid hydrogen through a circular annulus surrounding the sample chamber. High purity hydrogen or deuterium gas was then introduced into the sample chamber, and was allowed to condense in the sample chamber. A planar shock wave was generated by the high-speed impact of an aluminum-faced projectile onto the aluminum target body. The projectile is launched by a two-stage light-gas gun. The shock wave then reverberates between the two hydrogen-sapphire interfaces, thus compressing the thin hydrogen layer (initial thickness $=0.5 \mathrm{~mm}$ ) with a rapid series of shocks. The hydrogen sample remains in the high density multi-shocked state for approximately $400 \mathrm{nsec}$ before longitudinal and lateral release occurs. In this manner hydrogen pressures of over 1.2 Mbars were attained.

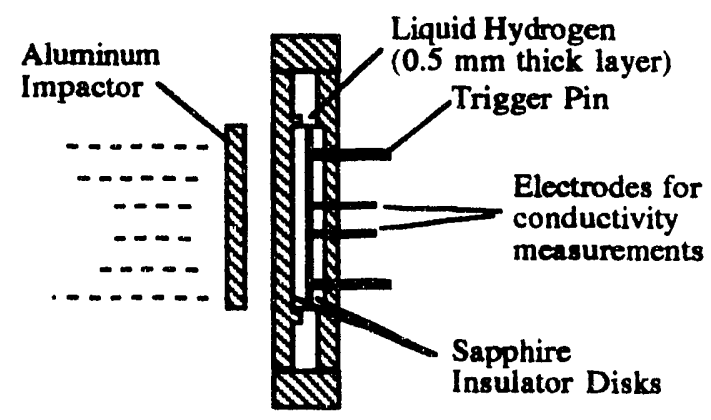

Figure 1. Target for electrical conductivity experiments on multi-shocked hydrogen. The shock wave generated by the aluminum impactor reverberates between the sapphire disks, thus compressing the hydrogen to high densities.

\section{Conductivity Measurements}

The electrical conductivity measurements were made using a constantvoltage or a constant-current circuit depending on whether the expected conductivity was greater than or less than approximately $1(\Omega-\mathrm{cm})^{-1}$. Precise impedance matching at all electrical connections was required to prevent signal ringing from interfering with the measurements. Triggering for this circuit was provided by either high-voltage or piezoelectric trigger pins which started the scope sweeps about 100 nsec before the expected signal. To maximize the dynamic range of the measurements, several scopes were used in parallel, with each scope adjusted to a different sensitivity. This large dynamic range was required because the conductivity changes by orders of magnitude throughout the pressure range explored, and so the widest possible dynamic range was needed to ensure that the signal was accurately measured.

Supplemental experiments performed to determine the resistivity of shocked sapphire revealed that the resistivity of sapphire is two to three orders of magnitude higher than the resistivity of $\mathrm{H}_{2}$ or $\mathrm{D}_{2}$ multi-shocked to the same pressure. Thus, conduction through the sapphire between the two electrical probes results in a small correction to the measured resistance, and very accurate measurements of hydrogen conductivity were possible.

The cell constant, a factor which relates the measured resistance to the sample resistivity, had to be determined for our sample-probe geometry. This cell constant was calculated in two different ways. First, the cell constant was experimentally measured by using standard electrolytic solutions of known conductivity. The cell constant was also determined by means of current flow computer simulations. These two methods yielded results in excellent agreement with each other for the specimen thicknesses at which both were performed. At the final densities of maximum compression, the three-dimensional calculated cell calibrations were used.

\section{RESULTS}

We have performed five multi-shock conductivity experiments on hydrogen thus far. The pressures range from 0.8 to 1.2 Mbars, and calculated temperatures 
are from $2000 \mathrm{~K}$ to $3000 \mathrm{~K}$. The calculated densities were near 0.3 moles $/ \mathrm{cm}^{3}$. The densities and temperatures were all calculated by 1-dimensional hydrocode simulations of the experiments using a fluid hydrogen equation-of-state (EOS) developed by G.I. Kerley ${ }^{16}$. This EOS, which is based on hard-sphere perturbation theory and the zero-Kelvin isotherm of the solid phase, is in excellent agreement with single- and double-shock hydrogen EOS experiments 1,17 . Calculations indicate that molecular dissociation is about $0.03 \%$ in our multishock experiments ${ }^{18}$, so a molecular model is valid. Both $\mathrm{H}_{2}$ and $\mathrm{D}_{2}$ were studied to check for consistency. Since the mass density of $D_{2}$ is about twice that of $\mathrm{H}_{2}, \mathrm{D}_{2}$ reaches a higher temperature than $\mathrm{H}_{2}$ multi-shocked to the same density.

In previous electrical conductivity experiments on singly-shocked hydrogen $^{9}$, it was found that the conductivity data could be interpreted in terms of a simple model for the conductivity of an intrinsic semiconductor at a non-zero temperature. Hydrogen is in a high density fluid ${ }^{19}$ state in our experiments, and for this case the conductivity is ${ }^{20}$

$$
\sigma=\sigma_{0} \exp \left(-E_{g} / 2 k_{b} T\right)
$$

where $E_{g}$ is the band gap, and $\sigma_{o}$ is a density-dependent parameter. Calculations of the band gap of fluid hydrogen at high densities have not been performed, so we make use of the best theoretical calculations available for the low-temperature solid phase.

Quasiparticle calculations ${ }^{14}$ have been performed on both c-axis orientationally ordered hcp hydrogen and orientationally disordered hcp hydrogen. The orientationally disordered case is expected to correspond most closely to the fluid case. Indeed, in the case of single-shock conductivity experiments 9 which compressed hydrogen to about $8 \mathrm{~cm}^{3} / \mathrm{mol}$, the energy gap calculated from Eqn. 1 $(11.7 \pm 1.1 \mathrm{eV})$ was found to be in good agreement with quasiparticle calculations of the band gap of orientationally disordered hcp hydrogen at the same density $\left(E_{g}=12 \mathrm{eV}\right)$. There is also good general agreement between this simple model and the multi-shock experiments, the experiments being consistent with a band gap in the 5-6 eV range for shock pressures in the range of $0.8-1.2 \mathrm{Mbars}$ and densities around $0.3 \mathrm{moles} / \mathrm{cm}^{3}$, although a discrepancy appears to be developing at higher densities, possibly because the actual band gap is less than the assumed calculated band gap for orientationally disordered hydrogen.

\section{SUMMARY}

We have performed quasi-isentropic multi-shock experiments on $\mathrm{H}_{2}$ and $\mathrm{D}_{2}$ at pressures up to $1.25 \mathrm{Mbar}$. Calculated temperatures were from $2000 \mathrm{~K}$ to 3000 $\mathrm{K}$, and the calculated densities were near $0.3 \mathrm{moles} / \mathrm{cm}^{3}$. These final state temperatures and densities were calculated using a 1-dimensional hydrocode with a fluid EOS based on hard-sphere perturbation theory ${ }^{16}$. Measured conductivities are in general agreement with a simple intrinsic semiconductor model with band gaps in the 5.2-6.0 eV range, as predicted by quasiparticle calculations for orientationally disordered hcp ${ }^{14}$.

\section{ACKNOWLEDGMENTS}

We thank N.W. Ashcroft, M. Ross, and $D$. Young for valuable discussions. We also gratefully thank R. Kays of Lockheed Missile \& Space Co. (Santa Cruz, CA) for providing us with liquid hydrogen for our experiments. Technical assistance was provided by J. Crawford, S. Weaver, E. See, and P.C.

McCandless. This work was performed under the auspices of the U.S.

Department of Energy by the Lawrence Livermore National Laboratory under contract No. W-7405-ENG-48, with support from the Director's Initiative LDRD committee. 


\section{REFERENCES}

[1] W.J. Nellis, A.C. Mitchell, M. van Thiel, G.J. Devine, R.J. Trainor, and N. Brown, J. Chem. Phys. 79, 1480 (1983).

[2] H.K. Mao, A.P. Jephcoat, R.J. Hemley, L.W. Finger, C.S. Zha, R.M. Hazen, and D.E. Cox, Science 239, 1131 (1981); R.M. Hazen, H.K. Mao, L.W. Finger, and R.J. Hemley, Phys. Rev. B 36, 3944 (1987).

[3] J. van Straaten and I. Silvera, Phys. Rev. B 37, 1989 (1988).

[4] R.J. Hemley and H.K. Mao, Phys. Rev. Lett. 61, 857 (1988).

[5] H.E. Lorenzana, I.F. Silvera, and K.A. Goettel, Phys. Rev. Lett. 63, 2080 (1989).

[6] H.E. Lorenzana, I.F. Silvera, and K.A. Goettel, Phys. Rev. Lett. 64, 1939 (1990).

[7] H.K. Mao, R.J. Hemley, and M. Hanfland, Phys. Rev. Lett. 65, 484 (1990).

[8] J.H. Eggert, F. Moshary, W.J. Evans, H.E. Lorenzana, K.A. Goettel, I.F. Silvera, and W.C. Moss, Phys. Rev. Lett. 66, 193 (1991).

[9] W.C. Nellis, A.C. Mitchell, P.C. McCandless, D.J. Erskine, and S.T. Weir, Phys. Rev. Lett. 68, 2937 (1992).

[10] E. Wigner and H.B. Huntington, J. Chem. Phys. 3, 764 (1935).

[11] C. Friedli and N.W. Ashcroft, Phys. Rev. B 16, 662 (1977).

[12] T.W. Barbee, III, A. Garcia, M.L.

Cohen, and J.L. Martins, Phys. Rev. Lett. 62, 1150 (1989).

[13] N.W. Ashcroft, Phys. Rev. B 41, 10963 (1990).

[14] H. Chacham and S.G. Louie, Phys. Rev. Lett. 66, 64 (1991).

[15] R.L. Kirk and D.J. Stevenson, Astrophys. J. 316, 836 (1987).

[16] G.I. Kerley, “A Model for the Calculation of Thermodynamic Properties of a Fluid using HardSphere Perturbation Theory and the Zero-Kelvin Isotherm of the Solid", in Molecular-Based Study of Fluids, Washington DC:

American Chem. Soc., 1983, pp. 107-138.

[17] R.D. Dick, Hydrogen Equation-ofState Data, in LASL Shock Hugoniot Data, S.P. Marsh, ed., Berkeley: UC Press, (1980).

[18] M. van Thiel, private communi cation.

[19] M. Ross, "Shock-Wave Studies: Modeling the Giant Planets", in High Pressure in Research and Industry, the Proceedings of the $8^{\text {th }}$ AIRAPT Conference, 1981, pp. 721-727.

[20] N.F. Mott, Philos. Mag. 24, 1 (197!). 

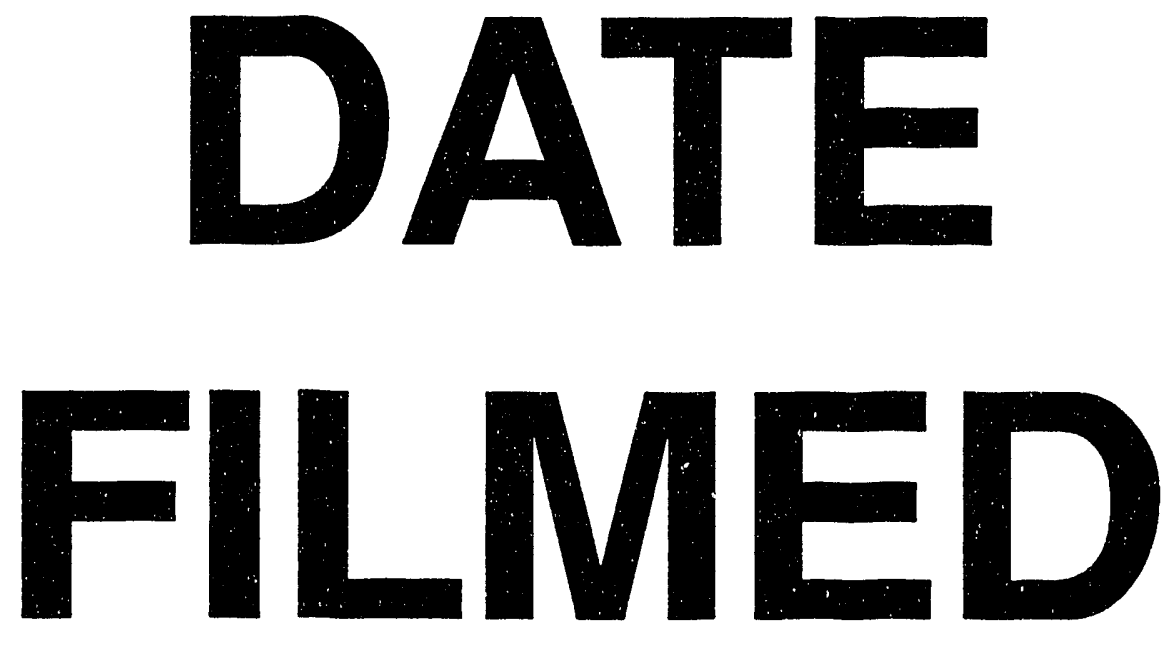

$6 / 10 / 94$
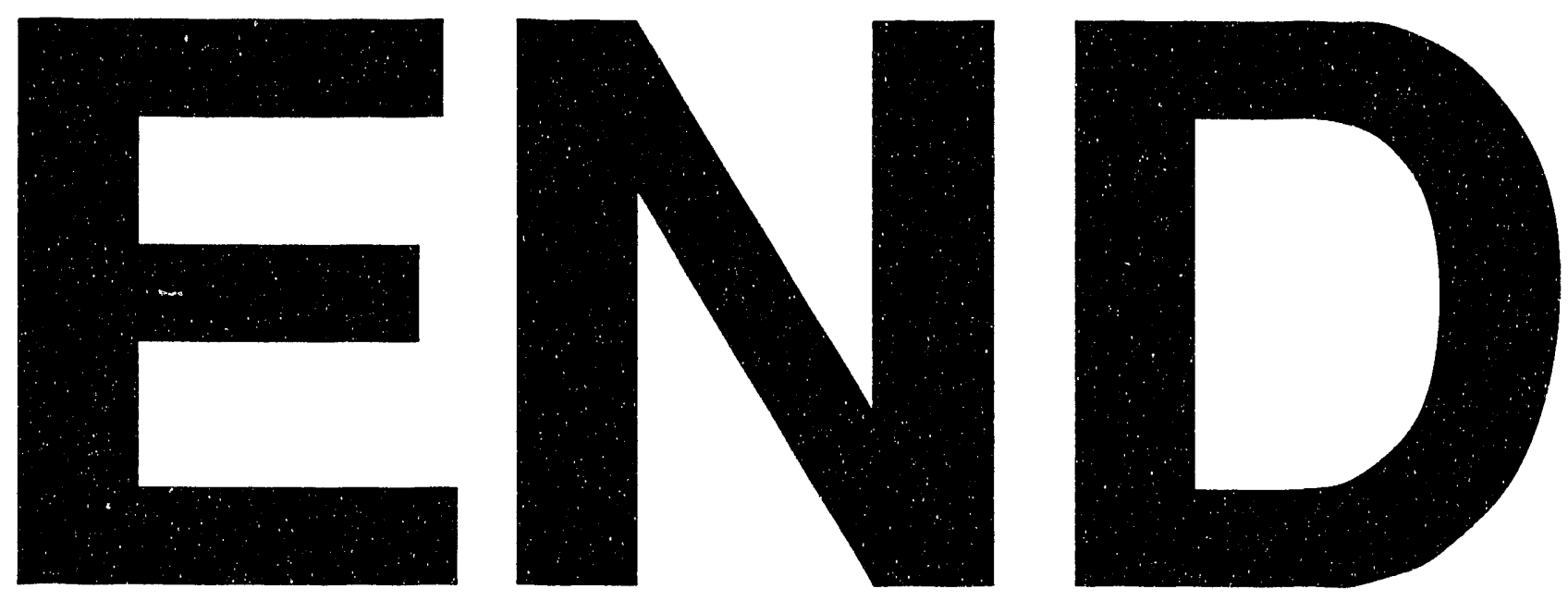


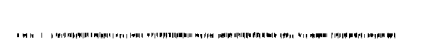

